\title{
Resisting the Perpetual Update: Struggles against Protocological Power in Video Games
}

\begin{abstract}
This article explores the evolution of video game updates and patches from a mechanism of customer support to a tool of control over the way games are played in the ecosystem of digital gaming platforms. It charts a historical trajectory across various cultural industries, including literary publishing, screen industries, and music, to show a shift from multiplicity of editions to one perpetually updated contingent commodity. Focusing on the issues of power and control enabled by the always-online platforms, the analysis shows that previously updating was often voluntary. However, now players must actively resist patches if they wish to play the game on their own terms. As illustrated by three case studies of update resistance, developers, publishers, and platform holders wield protocological power, which can be successfully opposed - although the outcome often remains localized and tends to alter a specific iteration of protocol and not the underlying infrastructure.
\end{abstract}

\section{Keywords}

patch, update, video games, protocol, protocological power, platform, digital distribution, user resistance, contingent commodity

Contemporary software clients and video game distribution platforms - starting with consoles such as Xbox 360 and with Steam - (see Kerr, 2017; Nieborg and Poell, 2018; O’Donnell, 2017) do more than ensure safe delivery of purchased software. They also strive to keep all owners of the game continuously updated, both in terms of news about the game as a commodity, and in terms of enforcing that players use the latest version of the game software. Due to online connectivity of these systems and the consequent rise of the "games as service” paradigm (Stenros and Sotamaa, 2009; Whitson, 2012), patches are downloaded and installed automatically. Players thus do not need to manually update their games and can use the gaming hardware or software for other purposes while the process of updating happens in the background. Under normal circumstances, this automation provides a smooth user experience as it delegates maintenance duties to gaming systems. At the same time, it provides platforms and software clients with access privileges to alter the game files. Traditionally, patches are believed to benefit the user, for example, by fixing bugs and performance issues. However, in reality many updates introduce significant changes beyond just technical improvements (see Guins, 2009; Heimo et al., 2016; Murphy, 2014; Paul, 2010; Sherlock, 2014; Zittrain 2008; anonymized reference 1 ). Whether it is removing old content, adding new one, altering game balance, or prohibiting certain player strategies, patches are not merely a quality of life support mechanism, but also a potent tool of creative expression and control. They turn games into so-called contingent commodities, which are subjected to constant and instantaneous revision by their producers (Nieborg and Poell, 2018; Zittrain 2008). In consequence, games become arenas of power struggle between players and official industrial actors. 


\section{A history of revisions}

Video games are not the first medium to be officially distributed in various iterations that share the same title and the majority of content. For example, literary publishing has already employed a similar practice of continuous updating in the form of later editions. New printings, including cheaper paperback versions or supposedly improved editions, were issued due to a variety of factors, such as the original print being sold out (Erickson, 2000; Feather, 2006), and not solely based on the desire to control the way a given book was read. Historically, the notion of authorial control over the meaning of a text was secondary to the publisher's economic interest. Nonetheless, new printings often came with corrections and updated paratextual elements, which in many cases addressed the initial audience reception and aimed to reinforce the official interpretation (Genette, 1997). However, due to the physical form of a codex book, old and new editions usually coexisted together as there was no easy or affordable way to retract the previous printings on behalf of the author, publishers, or regulatory bodies.

Beside an entirely new printing, iterations in literary publishing were also established by errata slips and inserts, which could be used to correct any mistakes found between the moment of manufacturing and distribution. Usually, literary errata dealt with technical errors, including typos or wrong page numbers. On their own, they did not automatically repair any mistakes but only listed the flaws and the corrections. It was up to the reader to take into account any information included in the errata and adjust the book accordingly (e.g. by making notes in it) or to keep it in mind as an additional set of instructions of how to engage with the book properly. Notably, analog game publishing also often relies on errata slips and inserts and even adopts the literary terminology by using the very same term (anonymized reference 2).

In pre-digital literary publishing, the act of updating required the agency of a reader, whether it was buying a new edition of the book or applying corrective paratextual elements such as errata. Also, purchasing the original version did not make its owner eligible for any free updates as is usually the case in modern video games with the exception of subscription-based games (Kerr, 2017).

Similar conventions of separately sold new versions have been established in the film industry. Here, the updates take the primary form of the so-called cuts (Gray, 2010). Usually, the initial theatrical version is in retrospect framed as compromised or unfinished compared to a more authentic DVD release (see Brereton, 2012; Gray, 2010; Klinger, 2006). However, as Pat Brereton further suggests, the abundance of different coexisting cuts actually works against the notion of one definitive version and ends up diversifying viewers' experiences.

In video games and software in general, one can also find different editions and versions that are sold or distributed separately (see Guins, 2014), including unauthorized clones (Fassone, 2017; Katzenbach et al., 2016; anonymized reference 3). For example, the socalled "Game of the Year" versions, sometimes also called "Gold” (Jett et al., 2016), use a similar model to DVD releases from screen industries. In place of extras, cast 
interviews, and alternative cuts, customers are offered the original game along with expansions and downloadable content (DLC), which were released after the launch. Nevertheless, as mentioned above, a large volume of updating happens behind the scenes and for free via patches and other similar updates.

There is no industry-wide consensus regarding how to call different types of patches. Some companies prefer calling them updates, for example Hello Games during the postrelease support of No Man's Sky (2016). Others stick to the term patch, including the highly-influential Blizzard Entertainment with games like World of Warcraft (2004) or Overwatch (2016). ${ }^{1}$ Certain development teams, for example Bungie - makers of Destiny 2 (2017) -, distinguish between regular patches/updates and hotfixes. Here, the main difference is the scope and timeline of such an update. Hotfix implies a more immediate patch that addresses a currently pressing issue or a bug (sometimes they can be also applied on the server side of the game without requiring any downloads on the side of the client), while regular patches encompass a larger amount of changes. The differences between the terms patch and update tend to be rather superficial and do not carry any specific rhetoric regarding the nature of the change. Patches might imply fixing and thus presuppose the existence of a bug or a glitch, while updates sound more neutral and additive instead of corrective. However, the actual use of the terms suggests that they function as synonyms (see Table 1). 
Table 1. Overview of official video game update-related phenomena.

\begin{tabular}{|c|c|c|}
\hline Type & Description & Equivalent \\
\hline Update & $\begin{array}{l}\text { Usually introduces new content, fixes } \\
\text { existing bugs and glitches, and adjusts game } \\
\text { balance. Requires download. Distributed for } \\
\text { free. }\end{array}$ & $\begin{array}{l}\text { Free replacement for faulty } \\
\text { components of an analog } \\
\text { game. }\end{array}$ \\
\hline Patch & $\begin{array}{l}\text { Usually fixes bugs and glitches, but can also } \\
\text { introduce new content and adjust game } \\
\text { balance. Requires download. Distributed for } \\
\text { free. }\end{array}$ & $\begin{array}{l}\text { Free replacement for faulty } \\
\text { components of an analog } \\
\text { game. }\end{array}$ \\
\hline Hotfix & $\begin{array}{l}\text { Fixes the most pressing bugs and issues. } \\
\text { Sometimes can be applied without } \\
\text { download. Distributed for free. }\end{array}$ & $\begin{array}{l}\text { Special tournament rulings, } \\
\text { ad hoc rules adjustments. }\end{array}$ \\
\hline $\begin{array}{l}\text { Day one } \\
\text { patch }\end{array}$ & $\begin{array}{l}\text { Allows for more production time for } \\
\text { developers and doubles as anti-piracy and } \\
\text { anti-leak protection. Often has significant } \\
\text { download size. Distributed for free. }\end{array}$ & $\begin{array}{l}\text { No equivalent in physically } \\
\text { distributed cultural } \\
\text { commodities. }\end{array}$ \\
\hline Edition & $\begin{array}{l}\text { Separately sold and distributed version of a } \\
\text { game either for the same platform or for } \\
\text { another one. Can include previously } \\
\text { released downloadable content, patches, and } \\
\text { updates. }\end{array}$ & $\begin{array}{l}\text { Later literary editions, } \\
\text { music remasters, film cuts. }\end{array}$ \\
\hline $\begin{array}{l}\text { Patch } \\
\text { notes }\end{array}$ & $\begin{array}{l}\text { A primarily verbal text that documents } \\
\text { changes made in an update, patch, or hotfix. } \\
\text { The level of technical detail and the degree } \\
\text { of rhetorical framing varies. }\end{array}$ & $\begin{array}{l}\text { Literary errata slip, analog } \\
\text { game errata. }\end{array}$ \\
\hline
\end{tabular}

A specific type of update is the so-called day one patch, which has become a common occurrence in mainstream video game publishing around 2014 (Narcisse, 2015). Day one patches serve two main functions. First, they can provide an additional layer of antipiracy control and serve as defense against leaks. ${ }^{2}$ Second, they give extra time to developers to fix bugs and to develop last-minute features even after the game master is sent for manufacturing or submitted for certification by platform holders such as Microsoft, Nintendo, or Sony. These patches can be large, in some cases nearing the entire install size of a given game (Yin-Poole, 2018), and they are usually automatically distributed and installed via digital gaming platforms on the official launch day. They can also be already included in the digitally distributed copies of the game.

Patches usually come in two components: as a software patch itself and as patch notes (also known as a change log or update history) - a text file describing and justifying the changes (Paul, 2010; Sherlock, 2014; anonymized reference 1). While patch notes can be ignored by users, patches tend to be applied automatically to software. This automated patch distribution is enabled by the prevalence of online digital gaming platforms in the video game industry (Hart, 2017; Kerr, 2017; Moore, 2009; Nieborg and Poell, 2018; O'Donnell, 2017; Toivonen and Sotamaa, 2010). It is also supported by the rise of the 
"games as service” paradigm (Stenros and Sotamaa, 2009; Whitson, 2012) - a production and distribution logic, within which developers deliver new content to players continually over time as opposed to a full definitive release of a game on a launch day. The resulting homogeneity of one official version across individual gaming machines, which is caused by updating, accentuates a shift from a game as a static physical object fixed on a storage medium (Guins, 2014) to a game as a contingent commodity (Nieborg and Poell, 2018; Zittrain 2008).

Platforms such as Netflix could also provide this functionality to creators in screen industries, but there is currently not enough empirical evidence to suggest that the TV and film content is being updated on a comparable scale to video games. However, exceptions can be found. For example, World War Z (2013) was reportedly first distributed in its theatrical version and later on was also made available in its unrated cut, at least on the Netflix US (Keating, 2015). Notably, music as a cultural commodity is becoming increasingly dependent on online connectivity and cloud services. In digital form, it becomes contingent and thus susceptible to revisions comparably to video games (Morris, 2015). At the same time, physical records and even locally stored music files still operate on the basis of multiple co-existing versions.

\section{Patches as control measures}

Before the advent of digital distribution of video games, developers decided what to patch largely based on internal testing and anecdotal feedback such as fan mail, phone calls, or online discussion forums. They were mostly observing what players themselves shared publicly: Users reported bugs as a form of consumer complaint, hoping that these would be fixed. This, for example, happened in one of the first documented cases of video game patches for the platformer Jet Set Willy (Software Projects, 1984) in 1984 (anonymized reference 4). Game balance issues, unless perceived as major design flaws, could be resolved without the involvement of the developers by introducing so-called house rules (i.e. player-made rules, which are rather common in analog gaming). Competitive play required more careful monitoring and regulation. But players usually subjected themselves to rules-enforcing authorities within their scenes and thus directly provided the necessary behavior data for balance patches, rule updates, or special tournament rulings (Harper, 2014).

Except for the subscription-based online games such as Ultima Online (Origin Systems, 1997), which were updated rather regularly already in the late 1990s (Kolo and Baur 2004), players needed to actively search for patches or buy a re-released updated version

of the game. ${ }^{3}$ Patches did not serve as tools of control but rather as a relatively pure form of post-release support. Of course, bug fixes could be coupled with more fundamental changes to game systems, which could, for example, disable some in-game exploits. Still, players were able to decide whether the technical and performance improvements outweighed any less desirable tweaks. In other words, developers and publishers could not easily force patches on players (Harper, 2014; Schmid, 2008) and had to provide a compelling case why to install the update or buy a later edition of the game. 
In comparison, the current networked structure of contemporary gaming platforms (starting with Steam and Xbox 360) provides much more information about how exactly people play games. This gives developers and publishers more incentive to control it, similarly to what was observed on a smaller scale within the genre of subscription-based online games. Currently, players are subjected to various forms of surveillance by platform holders and individual gaming companies (Canossa, 2014; Cybulski, 2014; De Paoli and Kerr, 2010; Murphy, 2014; Whitson, 2012). The data gathered this way now often serves as the basis for patches. We can thus observe a shift from qualitative user feedback towards quantitative analytics (Murphy, 2014; Nieborg and Poell, 2018; Whitson, 2012).

The autonomy to choose whether to update or not has been replaced by self-maintaining online gaming platforms and by the growing acceptance of the "games as service" paradigm by both the industry and the audiences. I argue that with this change, the general role of patches has evolved from technical support into a tool of iterative game design and control over the way the game is played. Updates still fulfill their previous functions but - due to their automated distribution and the increased oversight from developers and platform holders - they also provide the ability to regulate gameplay. In this regard, updates and patches resemble anti-cheating measures such as Blizzard Entertainment's Warden (De Paoli and Kerr, 2010). Virtual worlds, massivelymultiplayer online games, and subscription-based games in general were at the forefront of this change (Paul, 2010), but due to the proliferation of online gaming platforms this practice becomes increasingly more common in other genres. The current modes of control in the video game culture are not only caused by the monitoring and distribution technology, which allows this type of enforcement, but also by the gaming ethos characterized by often toxic insistence on meritocratic values and game design principles (Paul, 2018), which requires the same version of software to be run by all users in order to warrant a fair competition. Therefore, patches as a tool of control are not merely a technologically-determined consequence of digital distribution of games but also a cultural practice rooted in the history of social interactions and negotiations between various stakeholders.

As Raiford Guins (2009) points out, the impulse for regulation by patches does not always originate in the video game industry, as was the case in the Hot Coffee controversy surrounding Grand Theft Auto: San Andreas (Rockstar North, 2004). The titular Hot Coffee mod for the PC version of the game unlocked a sex mini-game, which could not be accessed by normal means but was still present in the code of the original release of the game across all platforms. Following public outcry and complaints from the US Congress, the publisher issued a patch for the PC version, which rendered Hot Coffee content completely inaccessible (Guins, 2009). At the time, this was an improvised solution aimed at appeasing the government as the installation of the patch was entirely voluntary. In 2005, there was no infrastructure to enforce it in a single-player game on PlayStation 2, Xbox, or even PC. This has changed with the introduction of digital distribution platforms such as Steam, which opened its marketplace to third-party publishers later that year. Subsequent editions of the game removed the controversial content altogether, but this only affected new customers. 
In his discussion of Hot Coffee and its impact on parental controls, Guins has argued that control technology would not lead to multiplicity of editions, as known from literary publishing, offline screen industries, or analog games, but to one sanitized version:

In the modulations of control, it is choice that is instrumentalized. Not unlimited choice, but delimited choice constitutes our relation to control technology. For film sanitizers, "choice is power." CleanFlicks and ClearPlay [film content filtering companies and services] offer their editing services as a form of corrective replacement, so it is doubtful that competing versions can coexist on the same storage medium. (Guins, 2009: 172)

In this regard, the contemporary practice of video game updates follows the logic of obsolescence and innovation established in other areas of technological development (Fitzpatrick, 2018; Slade, 2006; Sterne, 2007). With a release of a new patch, the previous version of the game becomes outdated and often loses some of its functionality, such as online connectivity or multiplayer capabilities. While the older versions might be documented and archived internally or externally (e.g. by fans in wikis), they are no longer easily accessible, especially for new players. The succession of patches is thus primarily a process of overwriting.

Unlike in the Hot Coffee case, parental controls and protection of minors from harmful content are nowadays rarely the main reason for patches. Bug fixes, performance improvements, and gameplay balance changes are among the main components of updates. With the advent of microtransactions (in-game purchases with real money) across all genres (anonymized reference 5), patches can also help to protect economic interests of publishers and developers, for example, by fixing exploits and glitches that could otherwise undermine in-game economy and producers' economic interests. Olli I. Heimo et al. have observed complaints against a patch for Clash of Clans (Supercell, 2012), which made

$[\ldots]$ the collecting of resources [...] harder-apparently to get players to buy the resources and thus pay more rather than having to collect the resources themselves. This caused players to complain that they had been misled and that the game provider was just being greedy [...] (Heimo et al., 2016: 7)

Thus, the notion that updates should always benefit the user is not universally true, as industrial actors sometimes leverage their privileged position to increase their profits at the expense of players.

\section{Protocological power}

This new form of control provided by patches in the era of digital distribution can be understood as a type of protocological power. In Protocol: How Control Exists after Decentralization, Alexander R. Galloway (2004) builds on Gilles Delueze's (1992) distinction between disciplinary societies and the contemporary societies of control, arguing that our present-day network societies (Castells, 2009) employ protocological 
rather than disciplinary power. This type of power is distributed throughout information networks via technical protocols, such as the interplay between TCP/IP (Transmission Control Protocol/Internet Protocol) and the DNS (Domain Name System), which together shape the hierarchy of the Internet.

In order for these systems to work properly, the same version of the protocol has to be installed on each node of the network. Protocological control is a "soft" type of power its acceptance brings significant advantages. Refusal of protocol may not be directly penalized (as would be the case if it was disciplinary power), but often causes partial or complete exclusion of a user/node from the network.

Not to enter into the protocological community carries such a high price that to reject protocol would be foolish. [...] Only the participants can connect, and therefore, by definition, there can be no resistance to protocol (at least not in any direct or connected sense). Opposing protocol is like opposing gravity - there is nothing that says it can't be done, but such a pursuit is surely misguided and in the end hasn't hurt gravity much.

(Galloway, 2004: 147)

In case of video games, continued customer support, online multiplayer capabilities, or community participation are predicated on being connected and subjected to updates. The self-updating nature of digital gaming platforms and software clients embodies the logic of protocol as a "technology of inclusion" (Galloway, 2004: 147). The default option is to stay connected. Opting out and disabling updates, which often leads to lack of functionality, requires agency on the side of the player. In the age of digital distribution of games, protocol is always present but its impact and implementation varies case by case as not all titles fully enact the network structures described by Galloway. Some games are partly autonomous objects and retain some degree of functionality even after being disconnected from the network. Others to a much more significant degree depend on a link to a host or specific nodes and thus more fully embrace the "games as service" paradigm, which in turn increases the reach of protocological power.

Galloway argues that "[t]he best tactical response to protocol is not resistance but hypertrophy." (2004: 244), which exploits the weaknesses of protocol and can take form of, for example, hacking or computer viruses. On a societal level, this hypertrophy can lead to rearticulation of the protocol. However, contemporary video games operate as relatively small networks run by private companies. As a result, developers and publishers also possess disciplinary power and are legally entitled to penalize certain types of software misuse, such as cheating (Consalvo, 2007; De Paoli and Kerr, 2010) or trolling (Cook et al., 2018). At the same time, video game cultural industry is shaped by interactions between producers, players, and other stakeholders (Kerr, 2006, 2017), and their negotiations can also happen outside of the protocological organization of a game. Thus, resistance does not necessarily have to be aimed at protocol as a type of controlling logic but at its current iteration. As I will show on this article's case studies, players can oppose an update of protocol without necessarily questioning the existence and legitimacy of protocol. 


\section{Power dynamics}

Relations between and among producers and audiences have legal and moral aspects. As such, the interactions do not always follow legal frameworks but instead rely on cultural negotiations and goodwill from both sides. This lack of established norms and procedures has been thoroughly discussed in the context of copyright protection. Both the fans and the intellectual property owners occasionally disregard apparently infringing cases, such as fan art or fan fiction, if they operate on a small scale or are entirely non-commercial (Schwabach, 2013; Tushnet, 2007). At the same time, modding projects often get shut down for alleged copyright infringement (Coleman and Dyer-Witheford, 2007; Postigo, 2008). This gray zone benefits large companies, which can afford legal counsel and litigation. In contrast, smaller independent creators struggle with the lack of copyright protection and have to appeal to their communities to help them fight against intellectual theft and imitation on the grounds of fairness (Dowthwaite et al., 2016; Van Roessel and Katzenbach, 2018).

Generally, software patches also invoke this type of power dynamic. Various empirical studies show that non-expert software users are reluctant to install patches themselves and that they are generally annoyed by update warnings (Fagan et al., 2015; Vaniea et al., 2014). The fact alone of needing to update and thus to abandon established user habits in order to keep using a game or a service can create unrest. In the realm of social media, top-down changes to privacy policies regularly incite protests, whether it was Facebook's introduction of the News Feed in 2006 (boyd, 2008) or Tinder's user profile revamp and stronger integration with other social networking sites in 2015 (Acker and Beaton, 2016). In most cases, these complaints challenge the update's fairness, not its legality.

This makes sense, since patches are usually legal due to end user license agreements (EULA) and terms of service (ToS), whose conditions users accept by playing the game. Video game companies are thus entitled to update and alter their games, but may eventually decide to revert controversial changes if they face strong opposition from players. Notably, the user reaction can take different forms from online protests (Acker and Beaton, 2016; boyd, 2008) to more private acts of opting out of patches, including workarounds, which subvert the expected outcome of an update in the sense of hypertrophy (Galloway, 2004). Save for a few exceptions (Boluk and LeMieux, 2017; Heimo et al., 2016; Murphy, 2014), the potential forms of resistance to video game updates is an underdeveloped area of empirical research. This article aims to treat this topic more systematically and compare different types of reactions and outcomes in order to better understand the power dynamics between producers and audiences in the context of protocological power.

\section{Three empirical cases of patch resistance}

\section{Methodology}

Due to the general lack of scholarly inquiry into video game update resistance, an exploratory design offers the best chance of understanding this area of video game 
culture. The information-oriented selection aimed for variation and diversity (Flyvbjerg, 2011; Schwandt and Gates, 2018) and was based on my experience as a player, scholar, and a former video game journalist. The cases do not attempt to fully capture all extreme scenarios of update enforcement and resistance, but instead intend to show concrete historical examples, which can illustrate the complexities of update culture and power relations between producers and users within digital gaming platforms.

The three games - Borderlands 2 (Gearbox Software, 2012), Counter-Strike: Global Offensive (Hidden Path Entertainment and Valve Corporation, 2012), and Marvel Strike Force (FoxNext, 2018) - represent three platforms (console, PC, ${ }^{4}$ and mobile, respectively), two major monetization models (premium and freemium), and different protocol infrastructures. Borderlands 2 is a multiplatform first-person shooter that allows for a four-player cooperative gameplay, but it can be also experienced solo and offline. Counter-Strike: Global Offensive (further abbreviated as CS:GO) is primarily a highly competitive PC player-versus-player multiplayer title with a strong eSports scene, including third-party servers. Lastly, Marvel Strike Force is a mobile turn-based strategy game that can be only played online using the official app.

The empirical analysis combines various qualitative research methods and different sources of material, including discourse analysis (Fairclough, 2003) of online discussions, digital ethnography (Murthy, 2008) of player communities centered around discussions forums, fan wikis, and streamers, and close readings of paratextual phenomena such as patch notes and social media posts by developers. The interpretation and discussion of these three case studies engages in both inductive and deductive approaches, utilizing the hands-on analytical methods and reflecting on the existing theory on protocol, patches, and the contingent commodity.

\section{Avoiding nerfs in Borderlands 2}

Borderlands 2 encourages repetitive gameplay, often called grinding or farming in the video game vernacular. This emphasis on repetition logically leads to playstyles focused on time efficiency. One of the popular items used for faster farming was the shield The Bee, which was changed in the PC patch 1.2.0 on November 13, 2012 (later released on consoles). The adjustments to the shield were communicated via patch notes:

Amplify damage from Amplify Shields [including The Bee] is now divided among all projectiles fired from a single shot.

Balance adjustments to "The Bee":

Increased Recharge Delay

Significantly increased Recharge Rate

Reduced Amplify damage (Gearbox Software Support, n.d.)

Even before the update, the shield has been widely discussed as potentially overpowered and countless online guides still explain how to obtain it. Randy Pitchford, the president of Gearbox Software, hinted at a balance fix roughly one month before the release of the patch in response to a fan on Twitter: "[...] Bee shield is so getting nerfed." (Pitchford, 
2012) After the patch, players kept discussing The Bee and debating whether the "nerf" a significant decrease in power - was justified.

The update seemed to mostly affect people playing the game solo, who were using the shield to quickly defeat high-level adversaries that were originally designed to be beaten with help from other players in a cooperative mode. Early on, a workaround has been discovered, which could eliminate the effects of the patch at least on PlayStation 3 and Xbox 360. By not installing the patch or deleting it (however along with all the previous updates), players could keep on using the original and more powerful version of The Bee.

Under normal circumstances when connected to the Internet, both consoles would prompt the player to download and install any available updates. However, users could temporarily disable the online connection of their gaming console to avoid pop-ups and interruptions. Besides being disconnected from the platform's network, such players also lost the option to play cooperatively and to access DLC. Thus, the previous version of the game remained playable but at the cost of limited functionality. Especially with more and more DLC being released after the patch 1.2.0, non-updating users were gradually pushed further away from the core of the active community because they could not access new expansions.

The complaints against the nerf never amounted to a full-fledged protest. One possible explanation is that players could relatively easily reject the patch within the boundaries of the game's protocol. It was mostly solo players who opposed the change and used the aforementioned workaround. Their playstyle was not significantly affected by the benevolent network structure of Borderlands 2, because they were not playing cooperatively in the first place and thus had less motivation to update.

\section{Rejecting an overpowered gun in Counter-Strike: Global Offensive}

Compared to Borderlands 2, CS:GO's network infrastructure is built around competitive online multiplayer and fair competition enabled by regular game balance adjustments issued by the developer. On December 8, 2015, Valve has released patch 1.35.1.2 "Winter Update", which among other changes added a powerful new gun - the R8 Revolver.

[R8 REVOLVER]

- Added a new secondary weapon, the R8 Revolver, which occupies the

Desert Eagle loadout slot. (Counter-Strike: Global Offensive, 2015b)

Soon afterwards, players began criticizing the arguably overpowered weapon online and calling for its removal or adjustment. This online resistance was reported by gaming media, which described it as peaceful and legitimate (see Grayson, 2015; McWhertor, 2015; Tassi, 2015). ${ }^{5}$ Sometimes, it employed humor to ridicule the update. Curiously, among the early protesters was also Markus Persson, the designer of Minecraft, whose tweet from December 9 (Notch, 2015) echoed the by-then memetic status of the revolver. Beside regular and celebrity users, eSports organizers ESL and ESEA also opposed the patch. The former company decided to run a major tournament using the pre-1.35.1.2 version of CS:GO (Kennigit, 2015) and the latter promised to remove the revolver from 
public matches run by their service if Valve does not address the criticism by December 14 (Sheffield, 2015). This overwhelmingly negative reaction to the update led to an official response from Valve on December 10:

On Tuesday [December 8, 2015] we shipped some major gameplay changes in CS:GO including the R8 Revolver, and players have been voicing legitimate concerns over the balance of the weapon as shipped. While it typically takes more time to generate enough data to drive an update [...], in this case it's clear that we got the damage wrong and can respond immediately. So today we're updating the R8 Revolver to bring its values to be more in line with other weapons: among other changes, its damage has been reduced and it takes slightly longer to fire. (CounterStrike: Global Offensive, 2015a)

In two days, concerned players and eSports organizers successfully reverted the update of protocol by voicing their opinion online and adjusting custom game versions. The resistance occurred to a large degree outside of the game itself, even though various community-introduced rules against the use of the revolver effectively functioned as an additional set of socially-enforced norms distributed through various networks and platforms, including CS:GO as such. The data analytics approach highlighted in David Murphy's (2014) account of the Call of Duty: Black Ops 2 patch controversy as both the rationale and justification for a patch was in this case overshadowed by an online protest, which is arguably harder to assess quantitatively. The developers themselves had to step outside the totality of protocol and momentarily abandon the impulse for quantitative user surveillance characteristic for the contingent commodity (Nieborg and Poell, 2018) to see what players perceived as a problem and how to remedy it. In a sense, the quick fix to the revolver has taken on a more traditional function of a patch as a means of technical support in the wake of a customer complaint. Yet, the timeline between the various updates was accelerated compared to the early days of the video game industry, in part due to the existence of the network infrastructure of Steam.

\section{Streamers against monetization updates in Marvel Strike Force}

Compared to the two previously discussed premium titles, Marvel Strike Force relies on microtransactions as its main source of revenue. In the "Developer Update \#2" (related to the 1.4.0 app version) from August 14, 2018, the studio FoxNext announced new in-game events:

The summer updates continue [...] with the arrival of the hottest team yet: Nick Fury and his Agents of S.H.I.E.L.D.! In this legendary event, [...] [o]utfit your Kree minions now, as it will be quite a challenge to unlock Fury. (Marvel Strike Force, 2018b)

As in the aforementioned case of Clash of Clans (Heimo et al., 2016), players perceived the update as a sign of aggressive monetization. The new events required extensive grinding or a significant financial investment on the side of the player in order to satisfyingly experience the newly added content. On August 23, two streamers Kraken OXTS86V and Seatin have decided to stop creating content about Marvel Strike Force as a direct response to this update (Kraken OXTS86V, 2018; Seatin Man Of Marvel Strike 
Force, 2018a). One day later, this protest was reported by the gaming press (Marshall, 2018). The departure of these two content creators was discussed on various forums and social media and was later addressed in a public message from the developers on August 31:

In recent weeks, we've seen your posts and videos both expressing concern and providing valuable feedback on certain events, features, and offers we've released recently [...] The requirement to collect Kree Minions to unlock Nick Fury was frustrating to some players [...] That, combined with the pure volume of events happening recently, has led many to feel there were simply too many heroes to build up in a short time frame. (Marvel Strike Force, 2018a)

Developers promised changes that would tone down the need for spending real money to access new content. Due to the general scope of the complaints, it is hard to assess the actual impact of the subsequent updates and whether the situation for players has improved. In this case, there was no singular issue that could be transparently adjusted in favor of the protesting players. However, Seatin returned to content creation on September 3 (Seatin Man Of Marvel Strike Force, 2018b), suggesting some improvement in the game's monetization model. ${ }^{6}$

The protest took place outside the game's protocol structure and it was carried out by high-profile players of Marvel Strike Force whose role as content creators can be under normal circumstances considered beneficial to developers (Taylor, 2018). Arguably, it can also serve as a bargaining chip in the interaction between the player community and the producers and a way to amplify user resistance. While the actual outcomes are hard to evaluate due to the complex monetization model of the game, the protest was at least successful in eliciting an official response and an explicit commitment to more affordable gameplay updates.

\section{Conclusion}

The world of video games can be understood as a cultural industry (Kerr, 2006, 2017) with ties to other fields of cultural production (Brookey, 2010). As I have shown, the idea of updating is shared among many industries. Historically, it often introduced multiplicity to audience experiences, but the recent evolution of patches shows a shift from games as rather static objects (Guins, 2014) to only one accessible, albeit perpetually updated, version of a cultural artifact. The current practice of updating highlighted throughout this article is a pervasive trend enabled by online connectivity. While its origins can be traced to subscription-based online games, perpetual updating now happens across genres, hardware platforms, and monetization models in accord with an overarching move towards the production and distribution logic of "games as service" (Stenros and Sotamaa, 2009; Whitson, 2012). However, this process, even in the context of video games, is at the moment far from finished. Games still appear in separate versions for different console generations, including Borderlands 2, whose more recent edition Borderlands: The Handsome Collection (Gearbox Software, 2015) includes the same gameplay patches but differs when it comes to resolution and framerate. Nonetheless, it 
can be argued that video games have popularized the model of contingent commodity, which has been recently shaping the cultural and media landscape across various fields, including news (Nieborg and Poell, 2018) and music (Morris, 2015).

As seen on the three cases of patch resistance, players and other stakeholders negotiate with publishers and developers - the controllers of protocological power - in settings that allow for different tactics of opposition partly based on how much producers embrace the "games as service” paradigm. In games like Borderlands 2, which gives players autonomy at least regarding offline modes, users can opt out of the perpetual loop of updating at a relatively low cost. Primarily online games, such as CS:GO and Marvel Strike Force, tend to be more centralized and thus easier to control using protocological power. By turning games into contingent commodities, developers and publishers can more easily observe and regulate what players are doing in a game. Economic interests now often overlap with what would have been previously understood as authorial control, especially in titles with microtransactions. The automated distribution of patches is an important part of this oversight and it is both enforced by protocol and a part of the protocological infrastructure itself. Players usually do not question the organizational logic of digital gaming platforms and software clients (or the notion of "games as service”) but instead reject individual changes introduced by updates.

Despite the concentration of protocological (and disciplinary) power in the hands of video game companies and platform holders, players, users, and other stakeholders still have a fighting chance to oppose particular iterations of protocol, even in games that operate as contingent commodities. However, as Galloway (2004) has argued, protocol cannot be effectively opposed from within. This partly explains why the resistance, especially in the cases of CS:GO and Marvel Strike Force, happened mostly outside of the games on social media as participation inside the network requires the acceptance of the latest version of protocol. The actual outcome of such player efforts is not necessarily dependent on the technological infrastructure or the distribution and production model of a given game but rather on social interactions between the involved parties. The success of the CS:GO protest might have been partly facilitated by the eSports organizers who had the privileged position and autonomy to run their own custom but high-profile versions of the game and thus ignore the most recent patch. In the case of Marvel Strike Force, content creators were at the forefront of the resistance and achieved partial success. However, even such triumphs of patch resistance only adjust certain details of the latest official iteration of the game but do not discourage the practice of updating as a major principle of the contingent commodity. There are also documented cases in which player resistance was rejected by developers (Murphy, 2014). The space for resistance within the increasingly popular "games as service” paradigm is thus limited. Using a specific non-updated version of such video games now requires a non-trivial amount of agency on the side of users and the success of resistance efforts depends on the ability to organize protests - ideally civil ones - outside the space of the game, out of reach of video game producers’ protocological power. 


\section{Notes}

1. On PC and Mac, Blizzard operates its own online distribution platform Blizzard Battle.net. On consoles and mobile operating systems, it also uses platform-specific tools to update its games.

2. Developers can make the game unplayable unless the player installs the day one patch, which can require authentication of a legally purchased copy.

3. Arguably, video game players would have searched for patches only if they had previously experienced problems during play, similarly to their analog game counterparts (anonymized reference 2).

4. CS:GO was also released for PlayStation 3 and Xbox 360, but has never been properly updated on these platforms.

5. This relatively peaceful resistance was in stark contrast to a widely covered toxic reaction caused by a patch for Call of Duty: Black Ops 2 (Murphy, 2014).

6. Seatin again stopped creating content for Marvel Strike Force on October 26, this time without an official explanation.

\section{References}

Anonymized reference 1. Book chapter about video game paratextual elements from 2016a with the author name anonymized.

Anonymized reference 2. Book chapter about board game errata from 2016b with the author name anonymized.

Anonymized reference 3. Book about video game history from 2018 with the author name anonymized.

Anonymized reference 4. Book chapter about Manic Miner from 2017a with the author name anonymized.

Anonymized reference 5. Book chapter about microtransactions from 2017b with the author name anonymized.

Acker A and Beaton B (2016) Software Update Unrest: The Recent Happenings Around Tinder and Tesla. In: 2016 49th Hawaii International Conference on System Sciences (HICSS), January 2016, pp. 1891-1900.

Boluk S and LeMieux P (2017) Metagaming: Playing, Competing, Spectating, Cheating, Trading, Making, and Breaking Videogames. Minneapolis: University of Minnesota Press.

Blizzard Entertainment (2004) World of Warcraft. Irvine, California: Blizzard Entertainment.

Blizzard Entertainment (2016) Overwatch. Irvine, California: Blizzard Entertainment.

boyd d (2008) Facebook’s Privacy Trainwreck: Exposure, Invasion, and Social Convergence. Convergence: The International Journal of Research into New Media Technologies 14(1): 13-20. 
Brereton P (2012) Smart Cinema, DVD Add-Ons and New Audience Pleasures. London: Palgrave Macmillan UK.

Brookey RA (2010) Hollywood gamers: digital convergence in the film and video game industries. Bloomington: Indiana University Press.

Bungie (2014) Destiny. Bellevue, Washington: Activision.

Canossa A (2014) Reporting from the Snooping Trenches: Changes in Attitudes and Perceptions Towards Behavior Tracking in Digital Games. Surveillance \& Society 12(3): 433-436.

Castells M (2009) The Rise of the Network Society. 2nd ed. The Information Age: Economy, Society, and Culture v. 1. Chichester, West Sussex; Malden, MA: Wiley-Blackwell.

Coleman S and Dyer-Witheford N (2007) Playing on the digital commons: collectivities, capital and contestation in videogame culture. Media, Culture \& Society 29(6): 934-953.

Consalvo M (2007) Cheating: gaining advantage in videogames. Cambridge, Massachusetts: MIT Press.

Cook C, Schaafsma J and Antheunis M (2018) Under the bridge: An in-depth examination of online trolling in the gaming context. New Media \& Society 20(9): 3323-3340.

Counter-Strike: Global Offensive (2015a) Damage Control. Available at: http://blog.counterstrike.net/index.php/2015/12/13366/ (accessed 6 August 2018).

Counter-Strike: Global Offensive (2015b) Release Notes for 12/8/2015. Available at: http://blog.counter-strike.net/index.php/2015/12/13325/ (accessed 6 August 2018).

Cybulski A (2014) Enclosures at Play: Surveillance in the Code and Culture of Videogames. Surveillance \& Society 12(3): 427-432.

De Paoli S and Kerr A (2010) The Assemblage of Cheating: How to Study Cheating as Imbroglio in MMORPGs. The Fibreculture Journal (16).

Deleuze G (1992) Postscript on the Societies of Control. October 59: 3-7.

Dowthwaite L, Houghton RJ and Mortier R (2016) How relevant is copyright to online artists? A qualitative study of understandings, coping strategies, and possible solutions. First Monday 21(5).

Erickson L (2000) The Economy of Literary Form: English Literature and the Industrialization of Publishing, 1800-1850. Baltimore, Maryland: Johns Hopkins University Press.

Fagan M, Khan MMH and Buck R (2015) A study of users' experiences and beliefs about software update messages. Computers in Human Behavior 51: 504-519.

Fairclough N (2003) Analysing discourse: textual analysis for social research. London; New York: Routledge.

Fassone R (2017) Cammelli and Attack of the Mutant Camels: A Variantology of Italian Video Games of the 1980s. Well Played 6(2): 55-71. 
Feather J (2006) A history of British publishing. 2nd ed. London; New York: Routledge.

Fitzpatrick K (2018) Obsolescence and Innovation in the Age of the Digital. In: Sayers J (ed.) The Routledge companion to media studies and digital humanities. New York: Routledge, Taylor \& Francis Group, pp. 329-335.

Flyvbjerg B (2011) Case Study. In: Denzin NK and Lincoln YS (eds) The SAGE Handbook of Qualitative Research. 4th edition. Los Angeles, London, New Delhi, Singapore, Washington DC: SAGE, pp. 301-316.

FoxNext (2018) Marvel Strike Force. Century City, California: FoxNext.

Galloway AR (2004) Protocol: how control exists after decentralization. Cambridge, Massachusetts: MIT Press.

Gearbox Software (2012) Borderlands 2. Frisco, Texas: 2K Games.

Gearbox Software (2015) Borderlands: The Handsome Collection. Frisco, Texas: 2K Games.

Gearbox Software Support (n.d.) PC Update / Hot Fix Information. Available at: http://gearboxsoftware.zendesk.com/hc/en-us/articles/205280050--PC-Update-Hot-FixInformation (accessed 3 August 2018).

Genette G (1997) Paratexts: Thresholds of Interpretation. Cambridge; New York, NY, USA: Cambridge University Press.

Gray J (2010) Show sold separately: promos, spoilers, and other media paratexts. New York: New York University Press.

Grayson N (2015) Counter-Strike Players Really Hate the Game’s New Gun. Steamed, 9 December. Available at: https://steamed.kotaku.com/counter-strike-players-really-hatethe-games-new-gun-1747153436 (accessed 7 August 2018).

Guins R (2009) Edited clean version: technology and the culture of control. Minneapolis: University of Minnesota Press.

Guins R (2014) Game After: A Cultural Study of Video Game Afterlife. Cambridge, Massachusetts: MIT Press.

Harper T (2014) The culture of digital fighting games: performance and practice. New York: Routledge, Taylor \& Francis Group.

Hart CB (2017) Introduction. In: Hart CB (ed.) The Evolution and Social Impact of Video Game Economics. Lanham, Maryland: Lexington Books, pp. VII-XIV.

Heimo OI, Harviainen JT, Kimppa KK, et al. (2016) Virtual to Virtuous Money: A Virtue Ethics Perspective on Video Game Business Logic. Journal of Business Ethics: 1-9.

Hello Games (2016) No Man’s Sky. Guildford: Hello Games.

Hidden Path Entertainment and Valve Corporation (2012) Counter-Strike: Global Offensive. Bellevue, Washington: Valve Corporation. 
Jett J, Sacchi S, Lee JH, et al. (2016) A conceptual model for video games and interactive media. Journal of the Association for Information Science and Technology 67(3): 505-517.

Katzenbach C, Herweg S and Van Roessel L (2016) Copies, Clones, and Genre Building: Discourses on Imitation and Innovation in Digital Games. International Journal of Communication 10: 838-859.

Keating L (2015) Stream these Zombie Movies and TV Shows On Netflix, Hulu and Amazon to Prepare for Arnold Schwarzenegger in 'Maggie'. Tech Times, 7 May. Available at: https://www.techtimes.com/articles/50796/20150507/stream-zombie-movies-tv-showsnetflix-hulu-amazon-prepare-maggie.htm (accessed 30 August 2018).

Kennigit (2015) r/GlobalOffensive - ESL Proleague Season 2 Finals will be played on the previous patch. Available at:

https://www.reddit.com/r/GlobalOffensive/comments/3w2bkm/esl_proleague_season_2_ finals_will_be_played_on/(accessed 6 August 2018).

Kerr A (2006) The Business and Culture of Digital Games: Gamework/Gameplay. London; Thousand Oaks, California: SAGE.

Kerr A (2017) Global games: production, circulation and policy in the networked era. New York: Routledge.

Klinger B (2006) Beyond the Multiplex: Cinema, New Technologies, and the Home. Berkeley: University of California Press.

Kolo C and Baur T (2004) Living a Virtual Life: Social Dynamics of Online Gaming. Game Studies 4(1).

Kraken OXTS86V (2018) Kraken Out - Marvel Strike Force - MSF. Available at: https://www.youtube.com/channel/UCAr_4nLlBF2x7mGE5_LoPmA (accessed 23 October 2018).

Marshall C (2018) Marvel Strike Force's microtransactions go beyond the mobile standard. Polygon, 24 August. Available at:

https://www.polygon.com/2018/8/24/17776974/marvel-strike-force-microtransactions (accessed 23 October 2018).

Marvel Strike Force (2018a) Community Message 8/31/2018. Available at: https://marvelstrikeforce.com/en/updates/community-message-8312018 (accessed 23 October 2018).

Marvel Strike Force (2018b) Developer Update \#2. Available at: https://marvelstrikeforce.com/en/updates/dev-blog-2 (accessed 23 October 2018).

McWhertor M (2015) Counter-Strike: GO’s new gun is causing some problems. Polygon, 9 December. Available at: https://www.polygon.com/2015/12/9/9880304/counter-strikego-r8-revolver-controversy (accessed 6 August 2018).

Moore CL (2009) Digital Games Distribution: The Presence of the Past and the Future of Obsolescence. M/C Journal 12(3). 
Morris JW (2015) Selling Digital Music, Formatting Culture. Oakland, California: University of California Press.

Murphy D (2014) Battle on the Metric Front: Dispatches from Call of Duty’s Update War. Game Studies 14(2).

Murthy D (2008) Digital Ethnography: An Examination of the Use of New Technologies for Social Research. Sociology 42(5): 837-855.

Narcisse E (2015) More Than a Third of 2014’s Big-Budget Games Got Day-One Patches. Kotaku, 18 February. Available at: http://kotaku.com/more-than-a-third-of-2014-s-bigbudget-games-got-day-on-1686398805 (accessed 6 August 2018).

Nieborg DB and Poell T (2018) The platformization of cultural production: Theorizing the contingent cultural commodity. New Media \& Society 20(11): 4275-4292.

Notch (2015) I'm so happy! I was looking forward to Valve either releasing Half-Life 3 or an unbalanced revolver, and I got my wish! In: @notch. Available at:

https://twitter.com/notch/status/674591552962961408 (accessed 6 August 2018).

O’Donnell C (2017) 'Show me the Money!' Shifting Fields of Capital in the Global Game Industry. In: Hart CB (ed.) The Evolution and Social Impact of Video Game Economics. Lanham, Maryland: Lexington Books, pp. 1-14.

Origin Systems (1997) Ultima Online. Austin, Texas: EA.

Paul CA (2010) Process, Paratexts, and Texts: Rhetorical Analysis and Virtual Worlds. Journal of Virtual Worlds Research 3(1).

Paul CA (2018) The toxic meritocracy of video games: why gaming culture is the worst. Minneapolis: University of Minnesota Press.

Pitchford R (2012) @AddyJohn_V Bee shield is so getting nerfed. In: @duvalmagic. Available at: https://twitter.com/duvalmagic/status/254666987479904256 (accessed 3 August 2018).

Postigo H (2008) Video Game Appropriation through Modifications: Attitudes Concerning Intellectual Property among Modders and Fans. Convergence: The International Journal of Research into New Media Technologies 14(1): 59-74.

Rockstar North (2004) Grand Theft Auto: San Andreas. Edinburgh: Rockstar Games.

Schmid R (2008) Real text in virtual worlds. Technical Communication 55(3): 277-284.

Schwabach A (2013) Fan Fiction and Copyright: Outsider Works and Intellectual Property Protection. Burlington, Vermont: Ashgate Publishing.

Schwandt TA and Gates EF (2018) Case Study Methodology. In: Denzin NK and Lincoln YS (eds) The SAGE Handbook of Qualitative Research. 5th edition. Los Angeles, London, New Delhi, Singapore, Washington DC, Melbourne: SAGE, pp. 600-630. 
Seatin Man Of Marvel Strike Force (2018a) Quitting Marvel Strike Force - A Goodbye from Seatin. Available at: https://www.youtube.com/watch?v=xfJ9a2Owaj4 (accessed 23 October 2018).

Seatin Man Of Marvel Strike Force (2018b) Seatin Returns To Marvel Strike Force - One Last Try - Developer Communication Recap. Available at: https://www.youtube.com/watch?v=Q-232HYlEVY (accessed 23 October 2018).

Sheffield B (2015) If the R8 Revolver does not see a balance update by Monday night, we will remove the gun from Pug/Scrims until they have a chance to update. In: @fewowns. Available at: https://twitter.com/fewowns/status/675012332011913216 (accessed 6 August 2018).

Sherlock LM (2014) Patching as Design Rhetoric: Tracing the Framing and Delivery of Iterative Content Documentation in Online Games. In: DeWinter J and Moeller RM (eds) Computer games and technical communication: critical methods \& applications at the intersection. Burlington, Vermont: Ashgate Publishing Company, pp. 157-169.

Slade G (2006) Made to break: technology and obsolescence in America. Cambridge, Massachusetts: Harvard University Press.

Software Projects (1984) Jet Set Willy. Liverpool: Software Projects.

Stenros J and Sotamaa O (2009) Commoditization of Helping Players Play: Rise of the Service Paradigm. In: Proceedings of the 2009 DiGRA International Conference: Breaking New Ground: Innovation in Games, Play, Practice and Theory, Brunel University, West London, 2009. Digital Games Research Association.

Sterne J (2007) Out with the Trash: On the Future of New Media. In: Acland CR (ed.) Residual media. Minneapolis: University of Minnesota Press, pp. 16-31.

Supercell (2012) Clash of Clans. Helsinki: Supercell.

Tassi P (2015) The R8 Revolver Has Completely Destabilized ‘Counter-Strike: GO’ [Updated]. Forbes, 10 December. Available at:

https://www.forbes.com/sites/insertcoin/2015/12/10/the-r8-revolver-has-completelydestabilized-counter-strike-go/\#cbca5de22dbe (accessed 7 August 2018).

Taylor TL (2018) Watch Me Play: Twitch and the Rise of Game Live Streaming. Princeton, New Jersey: Princeton University Press.

Toivonen S and Sotamaa O (2010) Digital Distribution of Games: The Players' Perspective. In: Proceedings of the International Academic Conference on the Future of Game Design and Technology, New York, NY, USA, 2010, pp. 199-206. Futureplay '10. ACM.

Tushnet R (2007) Payment in Credit: Copyright Law and Subcultural Creativity. Law and Contemporary Problems 70.

Van Roessel L and Katzenbach C (2018) Navigating the grey area: Game production between inspiration and imitation. Convergence: The International Journal of Research into New Media Technologies (Online First). 
Vaniea KE, Rader E and Wash R (2014) Betrayed by updates: how negative experiences affect future security. In: Proceedings of the SIGCHI Conference on Human Factors in Computing Systems, Toronto, 2014, pp. 2671-2674. ACM.

Whitson JR (2012) Game Design by Numbers: Instrumental Play and the Quantitative Shift in the Digital Game Industry. Dissertation. Carleton University, Ottawa, Ontario.

Yin-Poole W (2018) Fallout 76's first major patch is a whopping 47GB on console. Eurogamer, 19 November. Available at: https://www.eurogamer.net/articles/2018-11-19-fallout-76sfirst-major-patch-is-a-whopping-47gb (accessed 15 January 2019).

Zittrain J (2008) The Future of the Internet and How to Stop It. New Haven, Connecticut: Yale University Press. 